\title{
DERMATOFIBROSARCOMA PROTUBERANS: CASE REPORT WITH REVIEW OF LITERATURE
}

\author{
Rishikant Vashistha ${ }^{1}$, Suraj Jain², S.M. Datey ${ }^{3}$, Abhishek Kansal ${ }^{4}$, Raghavendra Singh Yadav ${ }^{5}$
}

\section{HOW TO CITE THIS ARTICLE:}

Rishikant Vashistha, Suraj Jain, S.M. Datey, Abhishek Kansal, Raghavendra Singh Yadav. "Dermatofibrosarcoma Protuberans: Case Report with Review of Literature". Journal of Evolution of Medical and Dental Sciences 2014; Vol. 3, Issue 06, February 10; Page: 1409-1412, DOI: 10.14260/jemds/2014/1999

\begin{abstract}
Dermatofibrosarcoma Protuberans is an uncommon clinical entity. Dermatofibrosarcoma Protuberans (DFSP) is a sarcoma that arises from the dermis and invades the deeper tissues. It is a locally aggressive which rarely metastasizes. DFSP is known for its tendency to recur after local excisions. It has variable presentations and is likely to be ignored by the patient for a long time because of its inconspicuous nature. We are presenting the case of a forty two year old female who came with a small nodular lesion over the sternal region without any symptoms, and on histopathology turned out to be a Dermatofibrosarcoma Protuberans.
\end{abstract}

KEYWORDS: Dermatofibrosarcoma Protuberans.

INTRODUCTION: Dermatofibrosarcoma Protuberans(DFSP) is an uncommon clinical entity, which is a sarcoma that arises from dermis and invades the deeper tissues. It is a locally aggressive malignancy which rarely metastasizes. It has a very high rate of recurrence after excision. Clinical presentation of this condition is variable. DFSP is a very slow growing malignancy and diagnosis is delayed for a long time. It may start as an inconspicuous lesion, e.g. a small asymptomatic papule or a non-indurated patch which is ignored by the patient. We are presenting the case of a forty two year old female who had a small lesion of about $2 \mathrm{~cm} x 2 \mathrm{~cm}$. on the sternal region which turned out to be a Dermatofibrosarcoma Protuberans.

\section{CASE REPORT:}

Forty two year old female presented with a small swelling over the sternal region which was about $5 \mathrm{~cm}$ below the suprasternal notch in the midline and of six months duration. There were no associated complaints of pain or discharge. Swelling had gradually increased in size to attain the present size of about $2 \mathrm{~cm}$. x $2 \mathrm{~cm}$.On palpation the local temperature was normal and the swelling was non-tender. This firm nodule was freely mobile and had pink and shiny overlying skin. Routine investigations were within normal limits. Fine Needle Aspiration Cytology was suggestive of Spindle Cell Tumor. Wide excision of the lesion was planned, which was done under local anesthesia with primary closure of the defect. The histopathological examination of the tissue revealed a Dermatofibrosarcoma

Clinical Photograph of Dermatofibrosarcoma Protuberans over sternal region

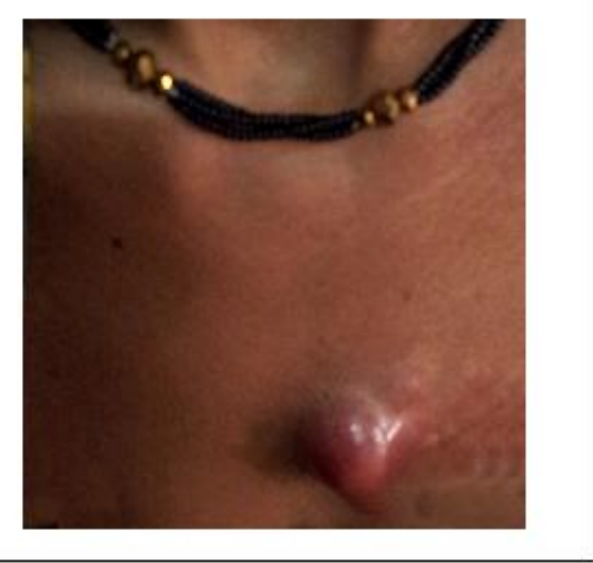
Protuberans. 


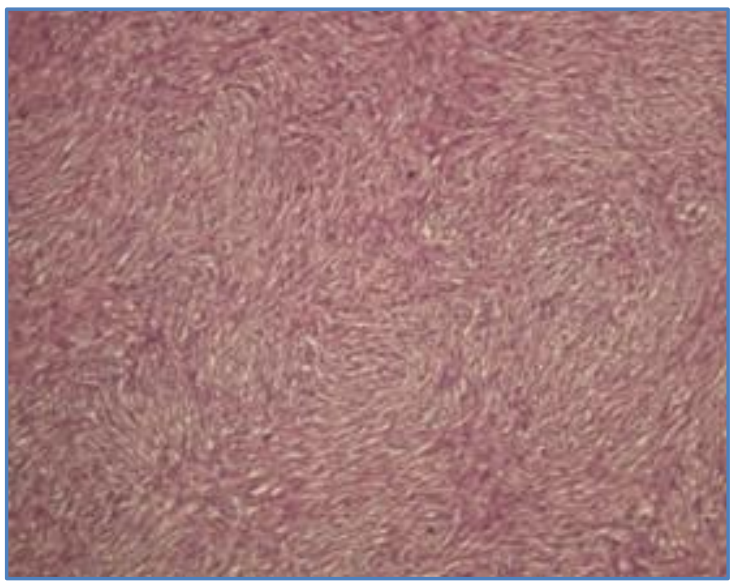

Microscopic Photograph of Dermatofibrosarcoma Protuberans

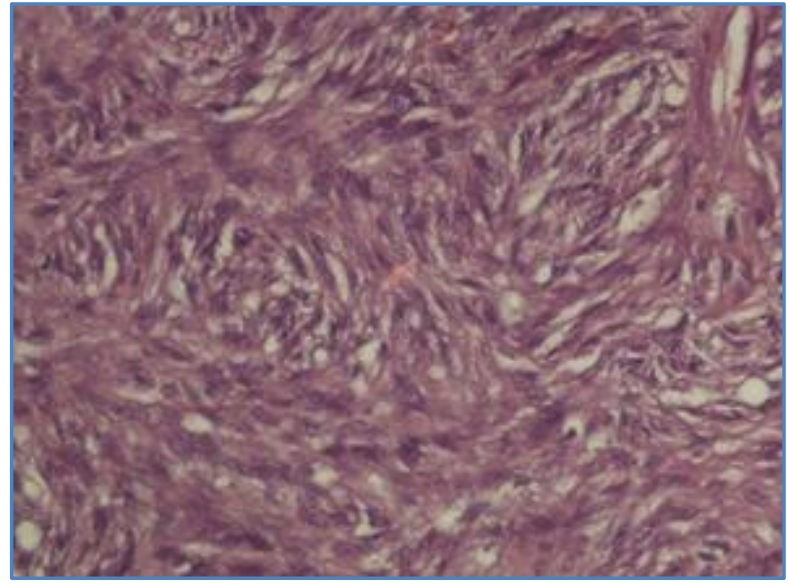

Microscopic Photograph of Dermatofibrosarcoma Protuberans

REVIEW OF LITERATURE: Dermatofibrosarcoma Protuberans (DFSP) starts as a very slow growing inconspicuous lesion of the skin. It does not give rise to any symptom and in the initial period the patient does not pay any attention to this problem. Although, the lesion does not metastasize and thus it is considered to be a low grade malignancy but a very high recurrence rate is observed after a local excision. We have reviewed the literature of this uncommon clinical entity for the benefit of all.

EPIDEMIOLOGY: Dermatofibrosarcoma Protuberans is a very uncommon type of sarcoma (soft tissue cancer).It comprises of less than $0.1 \%$ of all cancers and 4 to $5 \%$ of all soft tissue sarcomas. In two separate studies 0.5 to 5 cases per million population per year has been reported ${ }^{1}$. Commonly the age group between 20 to 50 is affected. Rarely newborns and elderly individuals are also affected ${ }^{2}$ Equal sex distribution with slight male predominance is observed. In a series of 902 patients, 514 males and 388 females are reported ${ }^{3}$.

PATHOLOGY: Dermatofibrosarcoma Protuberans (DFSP) is a cutaneous malignancy that arises from the dermis and invades deeper subcutaneous tissues(eg. fat, fascia, muscle, bone).Cellular origin of DFSP is not clear. Evidence suggests that origin could be from fibroblastic, histiocytic or neuroectodermal cells. Histologically lesion contains atypical spindle cells located around a core of collagen tissue. Genetically all DFSPs express CD34 which has been used to distinguish it from Benign Fibrous Histiocytoma ${ }^{4}$ Causation is not clear, chromosomal aberrations may contribute to the etiology. No familiar or hereditary predisposition is noted. In a series $10-20 \%$ of the patients were found to have the lesion in previous surgical scar, or an old burn scar, or a keloid, or a vaccination site.

CLINICAL PRESENTATION: DFSP may start as a small asymptomatic papule or a non-indurated patch which is ignored. It may enlarge to lumpy nodule or it may evolve Into an atrophic or sclerotic plaque. It grows sideways, The growth may be accelerated in pregnancy. In some cases it may present as fibrotic plaque of violaceous nodularity and ulcerates on fast growth. In the initial phase the tumor is mobile but as the disease advances the nodule becomes fixed to underlying structures like fascia or 
muscle. Commonly the lesions are seen on trunk (42-70\%), followed by proximal extremities (1630\%).DFSP rarely occurs on neck (10-16\%)ํ. Many lesions like Dermatofibroma, Epidermal inclusion cyst, Keloid, Hypertrophic scars, Malignant Melanoma and metastatic carcinoma come in the differential diagnosis of DFSP.

INVESTIGATIONS: Diagnosis is done by histopathological examination of the tissue. A diagnosed case or a case with recurred growth may be investigated for metastasis. There are no chemical tests or biological markers of this disease.

TREATMENT: Mainstay of the treatment for Dermatofibrosarcoma Protuberans is surgical excision. Wide local resection and primary reconstruction is a widely used surgical approach. Mohs surgery is recommended by many authorities 5 . Every effort should be made to achieve clear surgical margins keeping in mind the local aggressiveness of tumor and high potential of local recurrence. NCCN recommends wide local excision over Mohs surgery ${ }^{6}$.

Other options are chemo and radiotherapy. Postoperative chemotherapy comprises of treatment with Imitinib Mesylate7. Radiotherapy can be given when surgical margins are not clear or the patient has a local recurrence after previous excisional surgery. Detailed review of literature reveals that no prospective study has been done regarding the treatment protocol or study of outcome of various methods, probably because of uncommon nature of problem.

\section{REFERENCES:}

1. Lenn D, Mugge LO, Mentzel T, Hoffken K. Current treatment options in dermatofibrosarcoma protuberans. J Cancer Res Clin Oncol. May 2009;135 (5):653-665.

2. Dimitropolous VA. Dermatofibrosarcoma Protuberans. Dermatol Ther. Nov-Dec 2008; 21(6):428-432.

3. Rutger EJ, Kroon BB, Albus Lutter CE, Gortzak E. Dermatofibrosarcoma Protuberans: Treatment and Prognosis. Eur J Surg Oncol. Jun 1992; 18(3):241-248.

4. Gisselsen D, Hoglund M, O'Brien KP, Dumanski JP, Mertens F, Mandahl N. A case of dermatofibrosarcoma protuberans with a ring chromosome 5 and a rearranged chromosome 22 containing amplified COL1A1 and PDGFB sequences. Cancer Lett. Nov 27 1998;133(2):12934.

5. Gloster HM, Harris KR, Roenigk RK. A comparison between Mohs micrographic surgery and wide excision for the treatment of dermatofibrosarcoma protuberans. J Am Acad Dermatol. Jul 1996; 35(1):82-87.

6. Castle Ko, Guadagnolo BA, Tsai CJ et al. Dermatofibrosarcoma Protuberans: Long term outcomes of 53 patients treated with conservative surgery and radiation therapy. Int Radiat Oncol Biol Phys 2013; 86:585-590.

7. Mc Arthur G. Molecular targeted treatment for dermatofibrosarcoma protuberans. Semin Oncol 2004; 31:30-36. 


\section{AUTHORS:}

1. Rishikant Vashistha

2. Suraj Jain

3. S. M. Datey

4. Abhishek Kansal

5. Raghavendra Singh Yadav

\section{PARTICULARS OF CONTRIBUTORS:}

1. Assistant Professor, Department of General Surgery, Sri Aurobindo Medical College \& P.G. Institute (SAIMS), Indore (M.P.), India.

2. Assistant Professor, Department of General Surgery, Sri Aurobindo Medical College \& P.G. Institute (SAIMS), Indore (M.P.), India.

3. Professor, Department of General Surgery, Sri Aurobindo Medical College \& P.G. Institute (SAIMS), Indore (M.P.), India.
4. Assistant Professor, Department of General Surgery, Sri Aurobindo Medical College \& P.G. Institute (SAIMS), Indore (M.P.), India.

5. Resident, Department of General Surgery, Sri Aurobindo Medical College \& P.G. Institute (SAIMS), Indore (M.P.), India.

\section{NAME ADDRESS EMAIL ID OF THE \\ CORRESPONDING AUTHOR:}

Dr. Rishikant Vashistha,

2 BB, Slice No. 5 ,

Scheme No. 78, Vijay Nagar,

Indore, M.P., PIN - 452010.

E-mail: vashistha.rishikant@gmail.com

Date of Submission: 21/01/2014.

Date of Peer Review: 22/01/2014.

Date of Acceptance: 28/01/2014.

Date of Publishing: 05/02/2014. 